Robert Wolf

\title{
What Publishers Can Learn From Other Media Business Models
}

$\mathrm{I}$ was sitting on my couch watching a streaming movie from my Netflix account when it occurred to me that I haven't bought a physical copy of a movie in almost five years. At one time I had been collecting a selection of movies that I enjoyed on the off chance I might want to watch them again someday. But then a few years ago I signed up for Netflix and my movie habits have not been the same since.

For those of you not familiar with the Netflix model, the following is a simplified explanation. You choose a plan based on the number of movies you would like available at any one time, usually 1-3. Then you make a list of titles you're interested in; as those titles come available they will send them to your house in order of availability. It's not a perfect model. If I add a new release to my list I have no guarantee I will have it sent to me; more likely they will send one of the more available, less popular movies on my list, but eventually I will get that new release, albeit it may not be new by the time I get it. Netflix also offers a streaming video plan where you pay a small monthly fee to have access to thousands of streaming videos for older content.

In recent years I have dropped the DVD delivery part of my Netflix subscription and have chosen to use services such as Redbox

\section{The problem is the number of resources \\ available has grown \\ at a rate that is \\ impossible for libraries \\ to keep up with.}

or Blockbuster Express for new releases. These are kiosks located in high traffic areas where you can rent new releases for $\$ 1.00$ for a 24 -hour period, or only a quarter of the price of a traditional movie rental. Again, there is no guarantee you will get the newest release but it's much less hit-or-miss than Netflix was. Also, unlike with my Netflix account there is no monthly fee. So if I didn't feel like watching any movies this month I was stuck paying a fee for a service I didn't use. I still subscribe to the Netflix streaming video plan, which allows me to access a huge catalog of older movies and television shows on demand.

Between these two services I pay about $\$ 10.00$ a month for all my entertainment needs, whereas in the past when I was buying movies I would pay on average $\$ 15.00$ a movie. So in the end I have access to a collection that is an order of magnitude larger than my personal library ever was or ever could be, and it costs me less, not to mention I don't have to find space for all my movies.

\section{So what does this have to do with libraries?}

Traditionally, libraries have been concerned with two broad functions. First, they acquire resources and secondly, they make these resources accessible to their patrons. Now obviously this is an oversimplification of the role of a library but it is still accurate. The problem is the number of resources available has grown at a rate that is impossible for libraries to keep up with. According to Bowker, there were over three million new book titles published in 2010, which is as many or more than most ACRL collections. ${ }^{1}$ By 2009 , there were over 50 million journal articles published since 1665, when the first journals were published, and growing over 1.5 million articles per year which give us just about 53 million articles by the end of 2011. ${ }^{2}$ With ever decreasing or only marginally increasing library budgets there is no way a library can keep pace with the rate of publication. Obviously, even before the digital age, libraries couldn't purchase every book or journal published, but that was something our patrons were more willing to accept. Today patrons are less forgiving of the holes in our 
collections. There is an expectation that everything is digital, cheap, and easily accessible, and why not? They can get apps for their devices for $\$ 0.99$ and access information 24/7 from almost any location. Why shouldn't they be able to access any article, ebook, video, etc., at anytime from anywhere?

According to IDC, a market intelligence and advisory service, information storage costs $17 \%$ of what it did in 2005. ${ }^{3}$ Hardware continues to improve even as prices drop, yet libraries have not seen significant savings in our digital subscriptions. We continue to pay legacy pricing for journals and ebooks as if we're still getting physical copies and paying for the overhead associated with the printing process. Also, most publishers offer what I call the all-or-nothing model of access. Either you buy ownership to their entire collection at a discounted rate, of which on average $80 \%$ of the titles you don't want or need but it's still cheaper than buying titles individually, or you don't subscribe at all? Granted we are saving hundreds of thousands of dollars through our big deal packages, but do we really need all those titles? We are being forced to choose between ownership and inflated temporary access, neither of which we can continue to afford. If budget cuts force me to drop a big deal package then neither of us wins. Which brings me back to Netflix and Redbox: why can't publishers offer us an access-only model that is both economical to us and profitable to them? Isn't it better to have some business with a library even if on a small scale than none at all? If a publisher package costs $\$ 20,000$ a year for ownership and I don't have the funds to purchase the package, wouldn't it make good business sense to offer an access-only package at a drastically reduced rate? This way we both win. I can satisfy my user's information needs and the publisher gets money from me that they would not otherwise see. Why does it have to be all or nothing?

Why aren't there many accessonly subscriptions available outside of aggregator databases? Publishers need to find better ways of providing content at cheaper rates for those of us who only want access: $\$ 20$ $\$ 50$ for 24-hour access to a journal article is absurd. I don't care how prestigious the journal is, it's too much. Publishers could benefit from a Netflix or Redbox model, allowing libraries to subscribe to their content at a low rate for access to older content and to paying as needed for more recent content. Profits they lose by lowering the price could be made up by a higher volume of smaller transactions. Some publishers have begun to move away from this model but most have not. They need to look at models like Netflix and Redbox which provide cheap access to information and are still highly profitable. This would allow libraries to focus on their core collections while still offering access to a larger pool of resources. It is a potential win-win situation for libraries and publishers alike.

\section{References}

1 "Annual Book Production 2010," Accessed July 5 ${ }^{\text {th }}$, 2011, http://www. bowkerinfo.com/pubtrack/AnnualBookProduction2010/ISBN_Output_2002-2010.pdf.

${ }^{2}$ Arif Jinha (2010). "Article 50 million: an estimate of the number of scholarly articles in existence." Learned Publishing, 23 (3): 258-263.

${ }^{3}$ Gantz, John and Reinsel, David (2011). Extracting Values from Chaos. IDC iView. Accessed July 5, 2011 http://www.emc.com/collateral/ analyst-reports/idc-extracting-valuefrom-chaos-ar.pdf.

\section{Looking for help with collection development?}

If you want to expand your library's collection of novels set in North Carolina, you should visit the Read North Carolina Novels blog hosted by the North Carolina Collection at the University of North Carolina at Chapel Hill (http://www.lib. unc.edu/blogs/ncnovels/).

If your interest in North Caroliniana is more general, both the North Carolina Collection at East Carolina University and the North Carolina Collection at UNC-Chapel Hill regularly post lists of new additions to their collections.

The addresses for those sites are:

http://www.ecu.edu/cs-lib/ncc/profs.cfm

http://www.lib.unc.edu/blogs/ncm/index.php/whats-new-in-the-north-carolina-collection/ 